\title{
Adenomyosis and its impact on fertility
}

\author{
Jaanam Altaf Khan', Xia Wang ${ }^{2}$, Xiuli Wang ${ }^{2 *}$
}

\begin{abstract}
${ }^{1}$ The Department of Obstetrics and Gynecology, The First Affiliated Hospital of Nanjing Medical University, Nanjing, Jiangsu Province, China

${ }^{2}$ The Department of Gynecology, The First Affiliated Hospital of Nanjing Medical University, Nanjing, Jiangsu Province, China
\end{abstract}

Received: 24 August 2019

Accepted: 03 September 2019

\author{
*Correspondence: \\ Dr. Xiuli Wang, \\ E-mail: xuili_2266@163.com
}

Copyright: ( ) the author(s), publisher and licensee Medip Academy. This is an open-access article distributed under the terms of the Creative Commons Attribution Non-Commercial License, which permits unrestricted non-commercial use, distribution, and reproduction in any medium, provided the original work is properly cited.

\begin{abstract}
Adenomyosis is an estrogen dependent benign gynecological disease affecting women of reproductive age causing them to have an adverse effect. Symptoms in these patients include pelvic pain, menorrhagia, abnormal uterine bleeding and infertility. It has a negative impact on a woman's reproductive ability. The gold standard treatment for adenomyosis is hysterectomy for whom fertility is not an issue and for whom future pregnancy has no concerns, however females who wish to retain uterus for child bearing purposes the treatment seems to be very challenging. In this literature we will focus on how adenomyosis affects the reproductive outcome in women and what is its impact on the pregnancy rate also we will enlighten the pregnancy outcomes and pregnancy rate in patient with adenomyosis after various treatment Including the medical, surgical and in-vitro fertilization.
\end{abstract}

Keywords: Adenomyosis, Infertility, IVF, Pregnancy outcome

\section{INTRODUCTION}

Adenomyosis (AD) is one of the most common benign pathological disease found in gynecology department, It can be defined as the presence of ectopic stromal and endometrial gland in the layer of uterus known as myometrium resulting in an enlarged hyper trophic and hyper plastic uterus. ${ }^{1}$ Based on the characteristic and growth of adenomyosis it is categorized into two form the focal and the diffuse type, when the growth of ectopic endometrial and stromal glands are within the myometrium of the uterus it is referred to as the focal $\mathrm{AD}$, these are circumscribed and localized lesion can also be called as adenomyoma. When the ectopic endometrial glands and stroma are widely spread or distributed throughout the uterine surface it is referred to as diffuse AD. ${ }^{2}$ Since the diffuse type AD involves more than half of the myometrium it causes severe menstrual cramp and more aggravated symptoms in comparison to the focal type. Involvement in diffuse type of $\mathrm{AD}$ requires wide range of excision, Henceforth there are several limitations and complications in the outcomes based on the surgical and medical approach in the course of disease entity. AD generally falls into the population of middle aged females, women of reproductive age and females with multiple gestation, the prevalence rate of adenomyosis in general population accounts for about 18\%-66\%. ${ }^{3}$ Patients with $\mathrm{AD}$ often complains of hypermenorrhea (extensive menstruation), dysmenorrhea (painful menstruation) passage of blood clots during menstruation, heavy menstrual bleeding along with abnormal uterine bleeding, pelvic pain and dyspareunia (pain during sexual intercourse), infertility and miscarriage are some of the common symptoms which is experienced by these females. However, heavy bleeding accounts for the most common chief complaint in patients 
with $\mathrm{AD}$ and it has the greatest impact on the quality of life in these females, making them anemic, fatigue and less enthusiastic to carry out activities of daily life. ${ }^{4} \mathrm{AD}$ have been reported to have a negative impact on a female's child bearing capacity i.e it decreases the chances of spontaneous pregnancy, increases the frequency of abortion and thus leaves the women infertile, by far there is no evidence that can comply with the increase in pregnancy rate just by giving medical treatment alone to these patients. ${ }^{5}$ Treatment in these patients mainly depends upon the symptoms, severity and the desire to preserve fertility for child bearing purposes. Use of non-steroidal anti-inflammatory drugs (NSAIDs), Analgesics, oral contraceptives, progestin, gonadotropinreleasing hormone agonists (GnRHa), aromatase inhibitor, tranexamic acid, danazol, levonorgestrel intrauterine system (LNG-IUS), danazol-loaded intrauterine devices, uterine artery embolization are some of the conservative treatment used in these patients. ${ }^{6}$ Hysterectomy remains the Gold standard choice in females who don't desire future pregnancy, conservative surgeries such as uterine sparing surgery is also carried out on those females for whom fertility is a concern and those who desire for future pregnancy. The confirmatory histopathology diagnosis can only made after hysterectomy. However, imaging modalities like transvaginal sonography, MRI and 3D TVS are some of the tools used in the initial diagnosis of this disease.

\section{Reasons for female infertility caused by adenomyosis}

The chances of female getting adenomyosis generally increases when a woman is of advanced maternal age, as this disease affect the middle aged women so chances of it reciprocates. Previous studies have shown the interference of $\mathrm{AD}$ with embryo implantation, these females are more susceptible to increased chances of spontaneous abortion, they have comparatively lower chances of getting pregnant due to decreased rate of implantation per embryo transfer. ${ }^{7}$ Due to ectopic stromal and endometrial gland there is hypertrophy that changes the morphology of the musculature and the plasticity of the endometrial cavity which have a significant effect on the uterine contraction and fertility which perhaps doesn't result in a successful implantation. The junction zone thickness greatly varies in patient with $\mathrm{AD}$ to that in a normal female in whom the junction zone thickness is thin, consistent and regular having a maximum thickness of about (JZ median thickness 5.2) but in AD patients there was significant increment in the myometrium thickness which attributed to increased $\mathrm{JZ}$ in return which affects the fertility. When the JZ expands from slight to massive size it results in fibrosis and hyperplasia of the endometrial cavity which result in subsequent changes in the elasticity, plasticity and the contour of the uterine cavity which in turns affect the peristalsis and thus fertility. ${ }^{8}$ These changes in the JZ can be best visualized on Trans vaginal ultrasound (TVS), 3D - TVS or MRI. ${ }^{9}$ On magnetic resonance image when the thickness of JZ exceed to at least $12 \mathrm{~mm}$ or to the cut off value of $10 \mathrm{~mm}$, JZ AD is said to be present. ${ }^{10}$

\section{Adenomyosis and infertility}

Natural pregnancy rate and infertility rate of adenomyosis.

Studies have shown a decrease in the pregnancy rate (PR) in patients with $\mathrm{AD}$, some researchers have come to the conclusion that $\mathrm{AD}$ adversely affects the probability of getting pregnant and early pregnancy loses have also been significantly reported. ${ }^{11}$

Several studies also brought down to knowledge that the frequent miscarriage rate in patients with $\mathrm{AD}$ accounts for about $32 \%$ to that in women without $\mathrm{AD}$ which is $14 \% .{ }^{12}$ Preterm delivery, premature birth, premature rupture of membrane (PROM), preterm premature rupture of membrane (PPROM), recurrent implantation failure and spontaneous pregnancy loses are some of the complications whose risk is increased in $\mathrm{AD}$ patients. However, those patients who underwent surgery for myometrium resection and whose uterus was reconstructed using a "triple flap method" after a period of one year follow up there was a significant increase in the pregnancy rate of $61.5 \%$ and live birth rate of $53.8 \%$ with more than $75 \%$ pregnancy achieved by In Vitro fertilization no uterine rupture was noted in these patients during the course of pregnancy. ${ }^{13}$ Out of 103 Patients who underwent clinical adenomyomectomy, 70 of them conceived with a pregnancy rate of $30 \%$ in one year and the pregnancy was achieved with IVF. ${ }^{14}$ Studies have also reported the change in endometrial receptive marker in an adenomyotic endometrium thus stands another reason for failed implantation. ${ }^{15}$ No studies have shown the natural conception by these patients but have always shown a negative impact of AD on infertility.

\section{Reproductive outcomes of adenomyosis after surgery}

Gonadotropin-releasing hormone analog (GnRH-a) treatment before surgery or preparing the endometrium with GnRH-a for 24 weeks prior to surgery.

The use of (GnRH-a) in combination with estrogen have shown a positive role in pregnancy and has improved the chances of conception in several patients. ${ }^{16}$ As visualized by MRI the adenomyotic lesions have significantly decreased by the use of (GnRH -a). ${ }^{17}$ The use of it have also played a positive role on the markers of endometrial implantation. ${ }^{18}$ It is believed to decrease the size of Adenomyotic lesion, while the AD patients who underwent frozen embryo transfer whose endometrium was prepared with long term (GnRH-a) therapy before the Implantation showed better pregnancy rate in comparison to those in whom pre-treatment with ( $\mathrm{GnRH}-$ a) was not given. ${ }^{19}$ 


\section{Cytoreductive surgery}

This surgery approach can be an open surgery or the laproscopic one, the approach to $\mathrm{AD}$ tissue is similar to myomectomy which involves the same steps in surgery, after the excision of adenomyotic tissue or $\mathrm{AD}$ lesions, the uterine layers are often sutured back to restore the contour of the myometrium, the suture technique greatly varies with different types including the $U$ sutures, the figure of eight or interrupted suture. ${ }^{20}$ The incision made for excising the $\mathrm{AD}$ lesion also varies which includes the transverse $\mathrm{H}$ incision or just a transverse or Longitudinal incision or a wedged shaped incision. ${ }^{21}$ The approach and outcome is different in surgery of focal AD versus diffuse $\mathrm{AD}$, unlike the focal $\mathrm{AD}$ the adenomyotic lesion is not well circumscribed and doesn't have an obscure boundary it becomes difficult to completely excise the lesion without having to predict no postoperative or intra operative complications. Due to the wide excision in diffuse $\mathrm{AD}$ followed by uteroplasty the chances of uterine rupture is very high in comparison to the pregnancy outcome in focal $\mathrm{AD}$ patients, where conception outcomes after the cytoreductive surgery were believed to improve. The pregnancy outcome and the delivery rate after cytoreductive surgery was higher and also there was symptomatic relief of the clinical manifestations. ${ }^{22}$ Studies also concluded that the pregnancy outcome in older women i.e (more than 40 years old) were poor with very low pregnancy rate and thus infer that cytoreductive surgery have no impact on fertility for those women who are above 40 years old. Women who underwent surgery versus women who were only on $(\mathrm{GnRH}-\mathrm{a})$ treatment showed a higher delivery rate of $33 \%$ versus $8 \%$ in the surgery group. ${ }^{23}$ After the surgery the delivery and the pregnancy rate were higher in groups who used IVF/ICSI. Complications such as uterine rupture during pregnancy are most likely to be noticed in those cases when surgery was extensive in AD patients and cases of uterine rupture have been reported. $9-15 \mathrm{~mm}$ is the optimal wall thickness for prevention of uterine rupture and for conception following a cytoreductive surgery. ${ }^{24}$ Thus uterine conservative operative method in $\mathrm{AD}$ patient can be useful but uterine rupture and prerequisite management should be taken into consideration while operating such patients and following up these patients postoperatively. In comparison to women who are less than 39 years old versus women who are above 40 years old, the pregnancy rate was 41.3 and $3.7 \% .^{25}$ The symptoms of painful menstruation ameliorated after conservative surgery from 54.6 to $84.6 \%$, symptoms of menorrhagia bettered from $50-68.8 \%$ or even to $73.7 \%$, the pregnancy outcome also up regulated from $46.9 \%$ to $60.5 \% .^{26}$

\section{Reproductive outcomes in adenomyosis after In vitro fertilization}

Pregnancy rate in women of more than 40 years old compared to those in younger women is estimated to be $(3.7 \%$ versus $41.3 \%)$ with probability of 0.05 , females who are younger below the age of 39, the In vitro fertilization rate was $21.3 \%$ and the IVF pregnancy rate was $60 \%$, patients with a prior history of IVF failure showed the pregnancy rate of $(\mathrm{P}=0.02) .{ }^{27}$

\section{Reproductive outcomes with the use of medical treatment}

The management of patients with adenomyosis still remains controversial albeit there is no proper guideline to follow as a management for these patients. Medical management have always been useful in alleviating the symptoms but doesn't stand as a treatment in absolute cure, they are generally helpful in ameliorating the symptoms but of course cannot treat the disease. The role of NSAIDs, OCPs, levonorgestrel releasing intra uterine systems (LNG-IUS), progestin such as danazol, dienogest and $\mathrm{GnRH}$ analogues have no doubt helped in alleviating the symptoms of menorrhagia and pain, significant reduction in the size of adenomyotic lesion is noted with use of GnRH analogue, none of the medical treatment by far has reported to improve fertility outcome alone , except with the treatment of GnRH in combination with surgery has shown to have a positive result on the pregnancy outcome.

Their role on infertility is also very debatable especially when it comes to the use of GnRH analogue Vs without using $\mathrm{GnRH}$ analogue and its impact on fertility. Use of $\mathrm{GnRH}$ agonists such as nafarelin acetate or leuprolide acetate for a period of 24 weeks showed a spontaneous pregnancy in women with severe adenomyosis. ${ }^{28}$ Despite only being few cases or reports in support of this management there were relatively good results in fertility when GnRH analogues were tested both prior and after the surgery. Studies have shown that the chances of pregnancy in infertile females had drastically increased with the administration of GnRH before the cycles of IVF. ${ }^{29}$ Patients undergoing frozen embryo transfer (FET) with long term treatment with GnRH agonists and in whom the endometrium was prepared with hormone replacement therapy showed an improved pregnancy outcome. ${ }^{30}$

There was up-regulation of pregnancy rate after $\mathrm{GnRH}$ pre-treatment in women undergoing FET by $(39.5 \%)$ versus $(25.2 \%)$ without pre-treatment of $\mathrm{GnRH}$ analogue. ${ }^{31}$ On the contrary there are also studies that showed there is no improvement with the use of GnRH analogue pre-treatment in patients with IVF. With advantages of GnRH pre-treatment on fertility there is limitation too from its long term use. Mood instability, reduced mineral bone density, atrophy of genitalia, hypoestrogenic side effect such vasomotor syndrome are some of the side effect which is also related to the use of it, making it applicable only for a short period of time, plasma estradoil levels should be well monitored to prevent it from hypoestrogenic state and thus preventing its adverse effect while using the drug simultaneously for the therapeutic effect on adenomyosis. ${ }^{32}$ 


\section{DISCUSSION}

Adenomyosis is a benign disease of the uterine musculature in which the myometrium is invaginated by endometrial glands and stroma cells causing these women to have abnormal uterine bleeding, dysmenorrhea, heavy menstruation and dypareunia, it affects women of reproductive age and its most commonly seen in women of 30-40 age group. Adenomyosis have generally a poor pregnancy outcome and therefore it's one of the main causes of infertility. Due to lower implantation rate, increased miscarriage, and poor pregnancy outcome, women with adenomyosis have lower chances to conceive in comparison to non-adenomyotic females. The diagnosis of adenomyosis is confirmed by histopathology following a hysterectomy in women with severe symptoms of menorrhagia, heavy menstrual bleeding and pelvic pain. Concerning the treatment in patients with adenomyosis by far there is no international guideline which is to be followed in due course of the disease, treatments are given based on the severity of the disease, the symptomatic complain of the patients and the wish to conserve the uterus for childbearing purpose. Females dealing with infertility issues, the pretreatment of GnRHa in females undergoing frozen embryo transfer showed the highest chance of pregnancy, study by Niu also showed that pregnancy rates, implantation rate and ongoing pregnancies were higher in females whose endometrium was prepared for 6 months with GnRHa pre-treatment before undergoing frozen embryo transfer, in comparison to those in whom pretreatment of GnRHa was not given. ${ }^{33}$ Thus infer us that GnRHa pretreatment have a positive effect on fertility. Study conducted in 2014 regarding the effect of adenomyosis on IVF/ICS. It included 9 studies with IVF/ICS except the two case control study, 306 women out of 1865 were diagnosed with $\mathrm{AD}$, the authors came to the conclusion that $\mathrm{AD}$ adversely affect the chances of getting pregnant and increases the pregnancy loses. ${ }^{34}$

A retrospective case control study by Hashimoto A, recently showed $\mathrm{AD}$ is associated with increased risk of pre-eclampsia, increased second trimester miscarriage and placental malposition. ${ }^{35}$ There is an urgent requirement for a unanimous diagnostic criteria and a proper guideline for management in these patients, which will allow the clinicians and researchers to perform well conducted prospective studies on adenomyosis and its effectiveness of surgical treatment in dealing with pregnancy outcomes and fertility.

\section{CONCLUSION}

The management of adenomyosis is very challenging yet controversial, medical treatment proved to be effective in reducing the symptoms faced by these women in disease entity. Conservative surgery is offered to those for whom pregnancy is a concern on the contrary hysterectomy is the choice for whom fertility is not an issue for future pregnancy and for those who don't want to preserve the uterus, with concerns to fertility, conservative excisional methods are an option but due to high chance of uterine rupture these should be discussed with the patients beforehand. There is still limitation to support data for surgery effectiveness due to less cases and reports. Till now there is no confirmed treatment that has a direct effect on fertility with AD patients however improvement in the pregnancy outcomes have been noticed with few treatments discussed in this literature. More scientific trials and well-designed studies are required to put into consideration).

\section{ACKNOWLEDGMENTS}

This work was supported by the Scientific Research Project of Jiangsu Provincial Health Commission (H2018017), the second phase of Maternal and Child Health Key Talent Project of Jiangsu Province (FRC201709), the first phase of Maternal and Child Health Project of Jiangsu Province (F201619), the fifth phase of the "333 project" of Jiangsu Province (LGY2016003).

Authors acknowledge the immense help received from the scholars whose articles are cited and included in the references of this manuscript. The authors are also grateful to authors/ editors/ publishers of all those articles, journals and book from where the literature for this article has been reviewed and discussed.

\section{Funding: No funding sources \\ Conflict of interest: None declared \\ Ethical approval: Not required}

\section{REFERENCES}

1. Hiroshi $\mathrm{T}$, Hiroshi $\mathrm{K}$, Mari $\mathrm{K}$, Mikiko AS, Atsushi T, Takashi M, et al. Complications and outcomes of pregnant women with adenomyosis in Japan. Reprod Med Biol. 2017;16:330-6.

2. Bergeron C, Amant F, Ferenczy A. Pathology and physiopathology of adenomyosis. Best Pract Res Clin Obstet Gynaecol. 2006;20:511-21.

3. Vercellini P, Vigano P, Somigliana E. Adenomyosis: epidemiological factors. Best Pract Res Clin Obstet Gynaecol. 2006;20:465-77.

4. Peric H, Fraser IS. The symptomatology of adenomyosis. Best Pract Res Clin Obstet Gynaecol. 2006;20:547-55.

5. Streuli I, Dubuisson J, Santulli P, de Ziegler D, Batteux F, Chapron C. An update on the pharmacological management of adenomyosis. Expert Opin Pharmacother. 2014;15(16):2347-60.

6. Farquhar C, Brosens I. Medical and surgical manage ment of adenomyosis. Best Pract Res Clin Obstet Gynaecol. 2006;20(4):603-16.

7. Wang PH, Fuh JL, Chao HT, Liu WM, Cheng MH, Chao KC. Is the surgical approach benefcial to subfertile women with symptomatic extensive 
adenomyosis? J Obstet Gynaecol Res. 2009;35(3):495-502.

8. Kissler S, Hamscho N, Zangos S, Wiegratz I, Schlichter S, Menzel C, et al. Uterotubal transport disorder in adenomyosis and endometriosis: a cause for infertility. BJOG. 2006;113:902-8.

9. Rasmussen CK, Glavind J, Madsen LD, Uldbjerg N, Dueholm M. Repeatability of junctional zone measurements using 3-dimensional transvaginal sonography in healthy fertile women. J Ultrasound Med. 2016;35:1497-508.

10. Kunz G, Beil D, Huppert P, Noe M, Kissler S, Leyendecker G. Adenomyosis in endometriosis-prevalence and impact on fertility. Evidence from magnetic resonance imaging. Hum Reprod. 2005;20:2309-16

11. Vercellini P, Consonni D, Barbara G, Buggio L, Frattaruolo MP, Somigliana E. Adenomyosis and reproductive performance after surgery for rectovaginal and colorectal endometriosis: a systematic review and meta-analysis. Reprod Biomed Online. 2014;28:704-13.

12. Salim R, Riris S, Saab W, Abramov B, Khadum I, Serhal P. Adenomyosis reduces pregnancy rates in infertile women undergoing IVF. Reprod Biomed Online. 2012;25:273-7.

13. Osada H, Silber S, Kakinuma T, Nagaishi M, Kato K, Kato O. Surgical procedure to conserve the uterus for future pregnancy in patients suffering from massive adenomyosis. Reprod Biomed Online. 2011;22(1):94-9.

14. Saremi A, Bahrami H, Salehian P, Hakak N, Pooladi A. Treatment of adenomyomectomy in women with severe uterine adenomyosis using a novel technique. Reprod Biomed Online. 2014;28(6):753-60.

15. Campo S, Campo V, Benagiano G. Adenomyosis and infertility. Reprod Biomed Online. 2012;24:3546.

16. Pontis A, D'Alterio MN, Pirarba S, de Angelis C, Tinelli R, Angioni S. Adenomyosis: a systematic review of medical treatment. Gynecol Endocrinol. 2016:1-5.

17. Imaoka I, Ascher SM, Sugimura K, Takahashi K, Li $\mathrm{H}$, Cuomo $\mathrm{F}$, et al. MR imaging of diffuse adenomyosis changes after GnRH analog therapy. J Magnet Reson Imag. 2002;15:285-90.

18. Khan KN, Kitajima M, Hiraki K, Fujishita A, Nakashima M, Masuzaki H. Decreased expression of human heat shock protein 70 in the endometria and pathological lesions of women with adenomyosis and uterine myoma after GnRH agonist therapy. Eur J Obstet Gynecol Reprod Biol. 2015;187:6-13.

19. Niu Z, Chen Q, Sun Y, Feng Y. Long-term pituitary down regulation before frozen embryo transfer could improve pregnancy outcomes in women with adenomyosis. Gynecol Endocrinol. 2013;29:1026-30.

20. Huang X, Huang Q, Chen S, Zhang J, Lin K, Zhang $\mathrm{X}$. Efficacy of laparoscopic adenomyomectomy using double-flap method for diffuse uterine adenomyosis. BMC Women's Health. 2015;15:24.
21. Fujishita A, Masuzaki H, Khan KN, Kitajima M, Ishimaru T. Modified reduction surgery for adenomyosis. A preliminary report of the transverse $\mathrm{H}$ incision technique. Gynecol Obstet Invest. 2004;57:132-8.

22. Kishi Y, Yabuta M, Taniguchi F. Who will benefit from uterus-sparing surgery in adenomyosis-associated subfertility? Fertil Steril. 2014;102:802-7.e1.

23. Wang PH, Fuh JL, Chao HT, Liu WM, Cheng MH, Chao KC. Is the surgical approach beneficial to subfertile women with symptomatic extensive adenomyosis? J Obstet Gynaecol Res. 2009;35:495502.

24. Otsubo Y, Nishida M, Arai Y, Ichikawa R, Taneichi A, Sakanaka M. Association of uterine wall thickness with pregnancy outcome following uterinesparing surgery for diffuse uterine adenomyosis. Aust N Z J Obstet Gynaecol. 2016;56:88-91.

25. Tsui KH, Lee FK, Seow KM, Chang WC, Wang JW, Chen SU, et al. Conservative surgical treatment of adenomyosis to improve fertility: controversial values, indications, complications, and pregnancy outcomes. Taiwan J Obstet Gynecol. 2015;54(6):635-40.

26. Grimbizis GF, Mikos T, Tarlatzis B. Uterus-sparing operative treatment for adenomyosis. Fertil Steril. 2014;101(2):472-87.

27. Kishi Y, Yabuta M, Taniguchi F. Who will benefit from uterus sparing surgery in adenomyosisassociated subfertility? Fertil Steril. 2014;102(3):802-7.

28. Hirata JD, Moghissi KS, Ginsburg KA. Pregnancy after medical therapy of adenomyosis with a gonadotropin-releasing hormone agonist. Fertil Steril. 1993;59:444-5.

29. Devlieger R, D'Hooghe T, Timmerman D. Uterine adenomyosis in the infer tility clinic. Hum Reprod Update. 2003;9:139-47.

30. Niu Z, Chen Q, Sun Y, Feng Y. Long-term pituitary downregulation before frozen embryo transfer could improve pregnancy outcomes in women with adenomyosis. Gynecol Endocrinol. 2013;29:1026-30.

31. Park CW, Choi MH, Yang KM, Song IO. Pregnancy rate in women with adenomyosis undergoing fresh or frozen embryo transfer cycles following gonadotropin-releasing hormone agonist treatment. Clin Exp Reprod Med. 2016;43:169-73.

32. Streuli I, Dubuisson J, Santulli P, de Ziegler D, Batteux F, Chapron C. An update on the pharmacological management of adenomyosis. Expert Opin Pharmacother. 2014;15:2347-60.

33. Niu Z, Chen Q, Sun Y, Feng Y. Long-term pituitary down regulation before frozen embryo transfer could improve pregnancy outcomes in women with adenomyosis. Gynecol Endocrinol. 2013;29:1026-30.

34. Vercellini P, Consonni D, Dridi D, Bracco B, Frattaruolo MP, Somigliana E. Uterine adenomyosis and in vitro fertilization outcome: a systematic review and meta-analysis. Hum Reprod. 2014;29:964-77. 
35. Hashimoto A, Iriyama T, Sayama S. Adenomyosis and adverse perinatal outcomes: increased risk of second trimester miscarriage, preeclampsia, and placental malposition. J Matern Fetal Neonatal Med. 2018;31(3):364-9.
Cite this article as: Khan JA, Wang X, Wang X. Adenomyosis and its impact on fertility. Int J Reprod Contracept Obstet Gynecol 2019;8:4135-40. 